\title{
Structure and properties of arc evaporated nanoscale TiN/MoN multilayered systems
}

\author{
A.D. Pogrebnjak ${ }^{\text {a, } *}$, D. Eyidi ${ }^{b}$, G. Abadias ${ }^{\text {b }}$, O.V. Bondar ${ }^{\text {a,* }}$, V.M. Beresnev ${ }^{c}$, O.V. Sobol ${ }^{\text {d }}$ \\ a Sumy State University, 40007 Sumy, Ukraine \\ b $P^{\prime}$ Institute, University of Poitiers, Poitiers, Futuroscope, France \\ c Kharkiv National University, Kharkiv, Ukraine \\ d National Technical University "KhPI", Kharkiv, Ukraine
}

\section{A R T I C L E I N F O}

\section{Article history:}

Received 25 March 2014

Accepted 3 July 2014

Available online 6 September 2014

\section{Keywords:}

Hardness

Multilayers

$\mathrm{Mo}_{2} \mathrm{~N}$

TiN

Composition

Nanocomposite

\begin{abstract}
A B S T R A C T
Using vacuum-arc evaporation method we fabricated periodic multilayered TiN/MoN structures with different bilayer periods $\lambda$ ranging from 25 to $100 \mathrm{~nm}$. Rutherford backscattering (RBS), X-ray diffraction (XRD), scanning electron microscopy (SEM) as well as transmission electron microscopy (TEM) and microhardness measurements were used for investigations of composition, structure and mechanical properties of the multilayered coatings. We found that molybdenum nitride and titanium nitride layers grown on steel show local partial epitaxy and columnar growth across interfaces. A molybdenum-titanium carbide interlayer was evidenced between the substrate and the multilayer. Molybdenum nitride and titanium nitride layers contain small $(5-30 \mathrm{~nm})$ grains and are well crystallized with (100) preferred orientation. They were identified as stoichiometric fcc TiN and cubic $\gamma-\mathrm{Mo}_{2} \mathrm{~N}$. Non-cubic molybdenum nitride phases were also detected. The hardness of the obtained structures achieved great values and maximal hardness was 29-31 GPa for multilayered structure with $50 \mathrm{~nm}$ period. Hardness of the obtained coatings is $25 \%$ higher in comparison with initial single-layer nitride coatings, wherein plasticity index $(\mathrm{H} / \mathrm{E})$ of multilayered structure is 0.075 .
\end{abstract}

(c) 2014 Elsevier Ltd. All rights reserved.

\section{Introduction}

Refractory metals are widely used in modern materials science as basic elements for coatings with high functional properties, such as nitride coatings. Improving the properties of such coatings using multicomponent or multilayered systems is a very actual task nowadays.

Ion-plasma deposition or coating's deposition using vacuum arc cathode evaporation seems to be a very promising way of fabrication of protective coatings [1-12]. In the presented paper we investigated TiN/MoN multilayered coatings with different bilayer periods form 25 to $100 \mathrm{~nm}$.

We should point, that multilayered, multicomponent and nanostructured coatings are widely used in modern materials science for increasing of protective properties of different industrial products, and for improving their hardness, wear and corrosion resistance, oxidation resistance under the influence of high temperatures and so on [4-15].

\section{Experimental procedure}

TiN/MoN samples were deposited on A 570 Grade 36 and AISI M2 high speed cutting steel substrates (steel disks, diameter is not higher

\footnotetext{
* Corresponding authors.

E-mail addresses: alexp@i.ua (A.D. Pogrebnjak), oleksandr.v.bondar@gmail.com (O.V. Bondar).
}

than $30 \mathrm{~mm}, 5 \mathrm{~mm}$ thickness, in a delivery state - these samples were used for tribotechnical tests) under different deposition regimes. A second series of substrates with $2 \mathrm{~mm}$ thickness and $20 \mathrm{~mm}$ diameter were used for RBS, SEM, EDS, TEM, and nano- and microhardness tests. Substrate surface was treated using glow discharge in order to clean and activate it before deposition. For multilayer TiN/MoN coating deposition we used a vacuum-arc device Bulat-6 with two evaporators (Ti and Mo) [14], which allows deposition of nanostructured coatings in pulsed mode with variable pulse amplitude and pulse frequency. Fig. 1 shows a schematic of the deposition system. The vacuum chamber (1) (base pressure of the chamber was $0.001 \mathrm{~Pa}$ ) was equipped with a system of automatic nitrogen pressure control (2) and two evaporators consisting of Mo (3) and Ti (4) (purity of metallic target was 99.8\%). The substrate holder (5) was mounted on a rotating stainless steel plate $(300 \times 300 \mathrm{~mm})$ on which the substrates (6) were placed. BULAT- 6 was also equipped with DC voltage source (7), the value of which can be varied between 5 and $1000 \mathrm{~V}$, and high-voltage impulse generator (8) with adjustable voltage pulse amplitude of $0.5-2 \mathrm{kV}$ and repetition frequency of 5$7 \mathrm{kHz}$. The substrate cleaning process was carried out using molybdenum ions for 3-5 min, while applying a $1 \mathrm{kV}$ substrate potential. Further, nitrogen was injected into the chamber and nitrides of titanium and molybdenum were deposited on opposite substrate sides. When first layers had been finished, deposition stopped and substrates turned over on the angle of $180^{\circ}$. Then deposition started again. In this way, the 


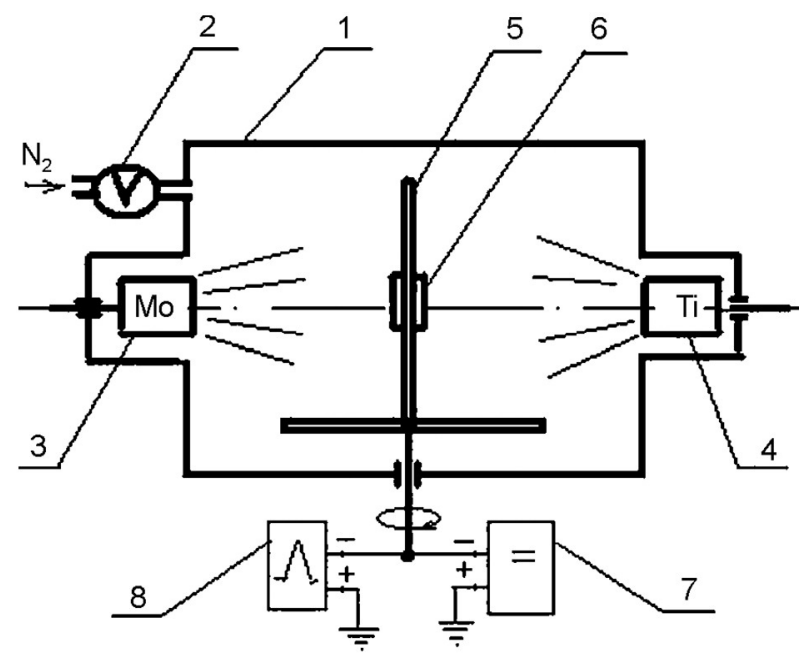

Fig. 1. Schematic representation of the "BULAT-6" deposition system (1 - vacuum chamber; 2 - automatic control system of the nitrogen pressure; 3 - molybdenum evaporator; 4 - titanium evaporator; 5 - substrate holder; 6 - substrate; 7 - DC voltage source; 8 high-voltage impulse generator).

average deposition speed was $1-2 \mathrm{~nm} / \mathrm{s}$. The arc current was 95-100 A during deposition, nitrogen pressure in the chamber was $0.5 \mathrm{~Pa}$, the distance between evaporator and substrate was $250 \mathrm{~mm}$ and substrate temperature was $250-350{ }^{\circ} \mathrm{C}$. During deposition of coatings a pulsed potential of $-40 \mathrm{~V}$ (with duration of $10 \mu$ s, repetition frequency $7 \mathrm{kHz}$ ) was applied to the substrate. The bilayer period $\lambda$ of the multilayer coating varied between 25 and $100 \mathrm{~nm}$ by changing the deposition time at fixed deposition conditions (see Table 1 ). Total thickness of the multilayered coatings was $6.8-8.2 \mu \mathrm{m}$.

To obtain full information about element composition of the coatings Rutherford Backscattering (RBS) technique was used. The $\mathrm{He}^{+}$ ion beam energy was fixed at $1.5 \mathrm{MeV}$, and the other experimental parameters having normal incidence of ions, a scattering angle $\theta=170^{\circ}$, He ions dose of $5 \mu \mathrm{C}$ and a detector energy resolution of $16 \mathrm{keV}$.

Microstructure and element composition investigations were done using several scanning electron microscopes (SEMs): Quanta 200 3D, Quanta 600 FE-SEM being equipped with PEGASUS $2000 \mathrm{X}$-ray detector, and a JEOL-7001F-TTLS with microanalysis Energy dispersive X-ray spectroscopy (EDS) unit. Depth profile analysis was done using $500 \mathrm{nA}$, and $1.72 \mathrm{keV} \mathrm{Ar}^{+}$primary ion beam at $45^{\circ}$ incidence angle. SAJW-05 SIMS analyzer was equipped by Physical Electronics 06-350E ion gun and QMA-410 Balzers quadrupole mass analyzer with $16 \mathrm{~mm}$ diameter rods. Structure and phase composition were studied by X-ray Diffraction (XRD) using a Bruker Advanced D8 goniometer operating in BraggBrentano configuration with $\mathrm{Cu}-\mathrm{K}_{\alpha}$ radiation. Diffraction profile allocation in the case of peak overlap was done using computer program "New_profile" (Ukrainian National Technical University "KhPI"). Volume fraction of phases in the coating was calculated using standard method, taking into account integral intensity. XRD stress analysis was carried out for the samples with the larger periods $(\lambda=50$ and $100 \mathrm{~nm})$ using the $\sin ^{2} \psi$ method [16]. Stress measurements were performed on a Seifert XRD diffractometer, operating at $40 \mathrm{~mA}$ and $40 \mathrm{kV}$, using point focus geometry with $\mathrm{Cu} X$-ray source, a $1.0 \mathrm{~mm}$ diameter collimator, a Ni filter to absorb the $\mathrm{Cu} \mathrm{K}_{\beta}$ wavelength and a scintillation detector. Measurements were taken by recording $2 \theta$ scans of the $\{200\}$ and $\{311\}$ TiN reflections at different specimen tilt angles $\psi$ ranging from 0 to $80^{\circ}$. Samples grown on steel were investigated by crosssectional transmission electron microscopy (XTEM) in high-resolution, bright-field, dark-field and selected area electron diffraction (SAED) modes using on a JEOL 2200-FS equipped with a field-emission gun and an omega energy filter. Images and diffraction patterns were filtered with a $10 \mathrm{eV}$ slit width around the zero-loss peak. Chemical mapping was made on a JEOL-2100 LaB6 machine equipped with a Jeol EDS system. Both TEMs were operated at $200 \mathrm{kV}$. Measurements of hardness and Young modulus were done using instrumented microhardness CSM REVETEST apparatus (Switzerland). Tribological tests were done using CSM Instruments tribometer. To provide such tests a probe was placed on the test sample and loaded with a precisely known weight. The sample was either rotating or reciprocating in a linear track. The resulting frictional forces acting between the probe and the sample were measured. Additionally, the wear for both the sample and probe was calculated from the volume of the material lost during the term of the test.

\section{Results and discussion}

The elemental composition of the samples was determined by RBS as well as EDS on cross-sectional images. RBS spectrum for TiN/MoN coatings with $\lambda=50 \mathrm{~nm}$ is presented in Fig. 2a. We can see kinematic factors for Ti and Mo near the surface, but we can also see "modulations" and we can estimate the thickness of individual layer from them. So, choosing the amount of channels and knowing ion loss per one channel we can evaluate an average thickness of the layer on the cross-section of the analyzing beam. So, we can state, that the thickness of MoN layer equals to $16.2 \mathrm{~nm}$. Using RBS spectrum data we can estimate the thickness of the first four layers from the surface, and we should point, that the thickness of TiN layer is $\sim 33.8 \mathrm{~nm}$, and it is more than twice the thicknesses of MoN layer. Results of SIMS analysis of the TiN/MoN coating with $\lambda=50 \mathrm{~nm}$ are presented in the inset of Fig. 2a. Taking into account ion's energy loss, detector's resolution and etching rate of $\mathrm{Ar}$ ions a value of $\lambda=48.7 \mathrm{~nm}$ is obtained, in good agreement with RBS data and SEM observations.

The XRD patterns of the TiN/MoN multilayers with $\lambda=25,50$ and $100 \mathrm{~nm}$ are reported in Fig. 2b. Two main reflections are observed around $2 \theta=36.5$ and $42.5^{\circ}$. A close inspection of the XRD line with the highest intensity shows that its profile is asymmetric and can be fitted using two contributions (see Fig. 2c and d), ascribed to (200) fcc TiN and (200) cubic $\gamma-\mathrm{Mo}_{2} \mathrm{~N}$ planes. The peak at $2 \theta=36.5$ is attributed to (111)-oriented TiN grains. These results suggest that TiN/MoN multilayers consist of highly-textured (200) cubic layers, if one compares to the intensity ratio expected for bulk polycrystalline reference powders.

The volume fraction of TiN and $\gamma-\mathrm{Mo}_{2} \mathrm{~N}$ phases was extracted from the XRD line fitting procedure of the (200) peak using the "New_profile" software. For $\lambda=25 \mathrm{~nm}$, a TiN/ $\gamma-\mathrm{Mo}_{2} \mathrm{~N}$ ratio of $90 / 10$ is obtained. Increasing the period of TiN/MoN layers up to $50 \mathrm{~nm}$ led to forming of two-phase structure state with an average content of TiN and $\gamma-\mathrm{Mo}_{2} \mathrm{~N}$ cubic phases equal to $60 \mathrm{vol} . \%$ and 40 vol.\%, which correlates with Ti and Mo concentrations, obtained using EDX, equal to 62.3 at.\% and 36.8 at.\% accordingly. For samples with more thick TiN and $\mathrm{Mo}_{2} \mathrm{~N}$ layers $(\lambda \approx 100 \mathrm{~nm}$ ) volume fraction of phases corresponds to EDX analysis data -70 at.\% for TiN and 30 at.\% for $\mathrm{Mo}_{2} \mathrm{~N}$.

Table 1

Parameters of coating's deposition.

\begin{tabular}{|c|c|c|c|c|c|c|c|c|c|}
\hline \multirow[t]{2}{*}{ No } & \multirow[t]{2}{*}{ Material } & \multicolumn{2}{|c|}{ Period, $\lambda$ nm } & \multirow[t]{2}{*}{$\mathrm{I}, \mathrm{A}$} & \multirow[t]{2}{*}{ Time, s, Ti/Mo } & \multirow[t]{2}{*}{$\mathrm{U}_{\text {bias, }}, \mathrm{V}$} & \multirow[t]{2}{*}{$\mathrm{U}, \mathrm{V}$} & \multirow[t]{2}{*}{ Pulse frequency, kHz } & \multirow[t]{2}{*}{ Pressure, $\mathrm{Pa}$} \\
\hline & & Expected & Measured & & & & & & \\
\hline 1 & TiN/MoN & 20 & $25 \pm 1.5$ & $95-100$ & $10 / 10$ & -40 & 1000 & 7 & 0.5 \\
\hline 2 & TiN/MoN & 40 & $50 \pm 2.2$ & $95-100$ & $20 / 20$ & -40 & 1000 & 7 & 0.5 \\
\hline 3 & TiN/MoN & 80 & $100 \pm 3.8$ & $95-100$ & $40 / 40$ & -40 & 1000 & 7 & 0.5 \\
\hline
\end{tabular}



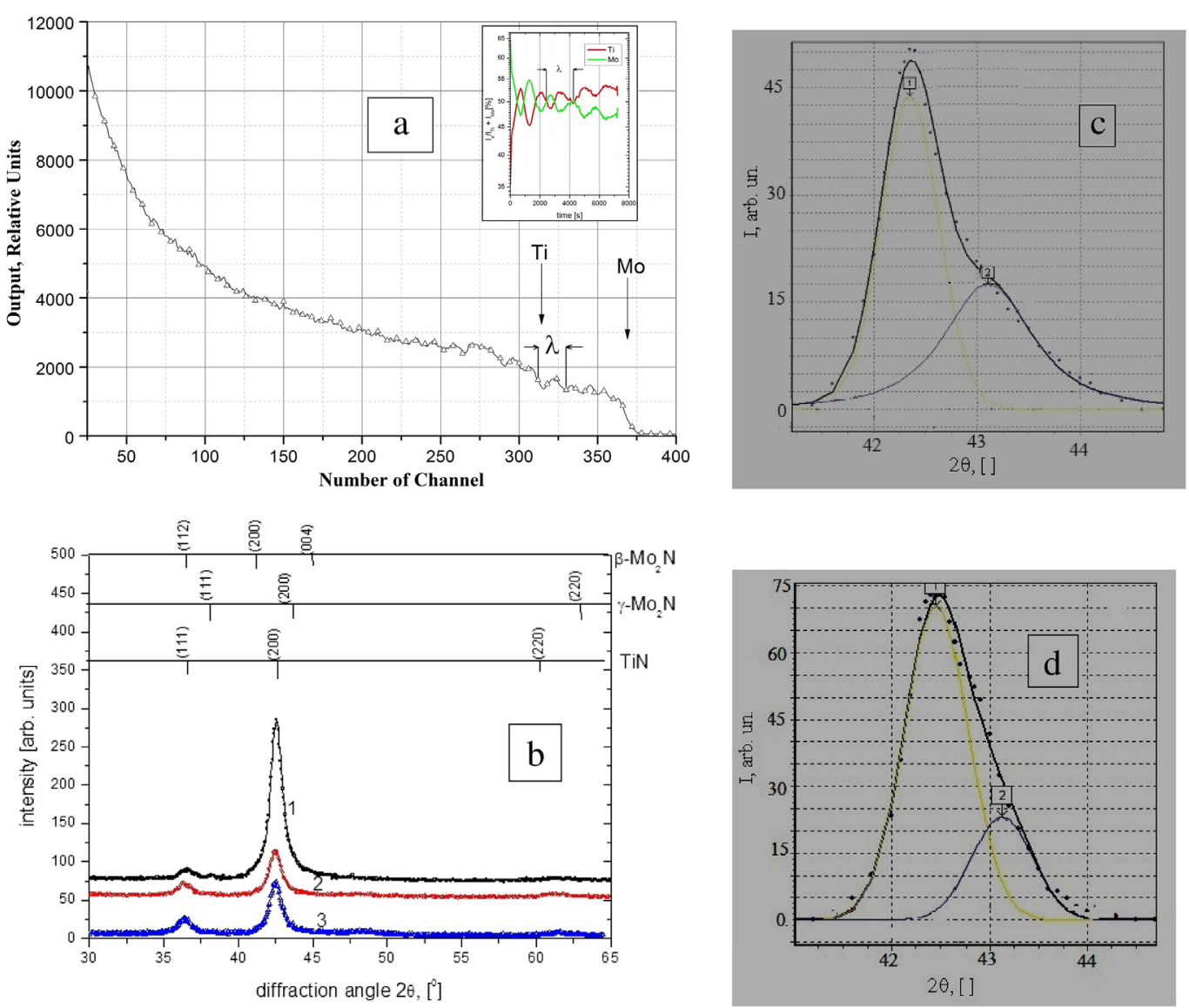

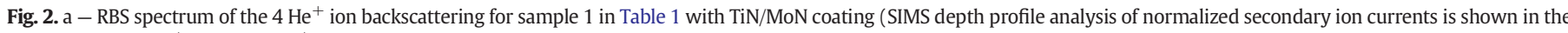

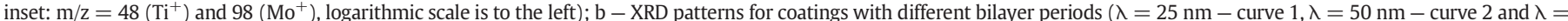

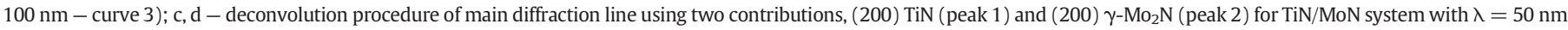
(c) and $\lambda=100 \mathrm{~nm}(\mathrm{~d})$.

It should be noted that in molybdenum nitride layers only the $\gamma$ $\mathrm{Mo}_{2} \mathrm{~N}$ with cubic, $\mathrm{Na}-\mathrm{Cl}$ type lattice was formed while the $\beta-\mathrm{Mo}_{2} \mathrm{~N}$ phase (tetragonal lattice) cannot be seen using XRD despite of the fact that both phases can be formed in the case of coating' deposition using vacuum-arc method and magnetron sputtering. It can be explained by two-stage process of forming of phase composition of the multilayered coating. In the early growth stage, a template effect

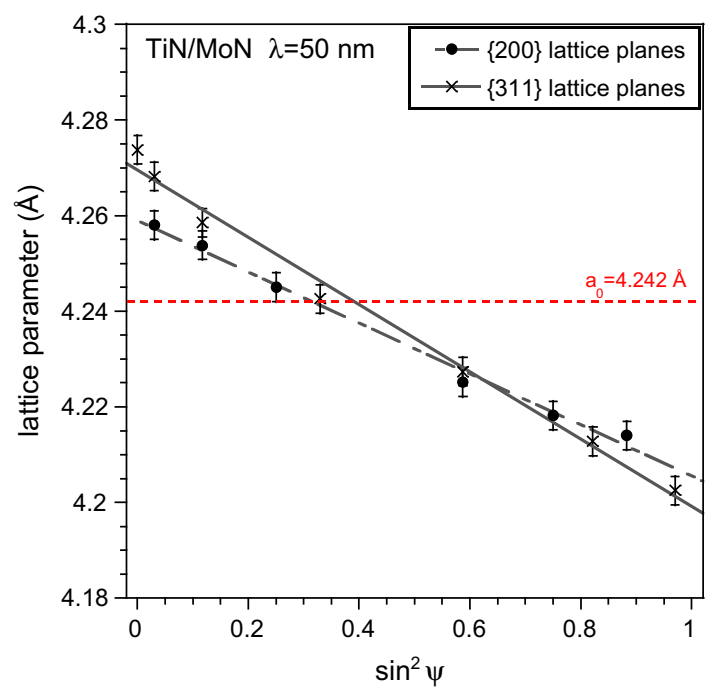

Fig. 3. $\sin ^{2} \psi$ plot for the TiN layers of the TiN/MoN multilayer with $\lambda=50 \mathrm{~nm}$. Data are reported for two $\{\mathrm{hkl}\}$ lattice planes of TiN layer. occurs due to small lattice mismatch $(<2 \%)$ between cubic TiN $\left(\mathrm{a}_{\mathrm{TiN}}=0.4242 \mathrm{~nm}\right.$, see JCPDS file no. 38-1420) and cubic $\mathrm{Mo}_{2} \mathrm{~N}$ $\left(\mathrm{a}_{\mathrm{Mo}_{2} \mathrm{~N}}=0.4163 \mathrm{~nm}\right.$, see JCPDS file no. 25-1366) phases, promoting the stabilization of $\gamma-\mathrm{Mo}_{2} \mathrm{~N}$ cubic modification by atomic registry.

Fig. 3 shows the evolution of the lattice parameter of TiN crystallites measured from (200) and (311) interplanar spacings as a function of $\sin ^{2} \psi$ for the TiN/MoN multilayer with $\lambda=50 \mathrm{~nm}$. It is clear in view of the negative slopes that the TiN layers are compressively stressed. The $\sin ^{2} \psi$ plots exhibit a rather fair linear variation, suggesting that stress gradient is negligible and/or no significant elastic anisotropy exists at the macroscopic level, despite the (200) preferred orientation of TiN layers observed in Fig. 1b. The stress analysis was therefore performed assuming a macroscopically (elastically) isotropic specimen, subjected to a rotationally symmetric in-plane biaxial stress state, $\sigma_{1}=\sigma_{2}=\sigma_{\text {biax }}$. For a cubic material, the strain-stress relation is given by

$\varepsilon_{\mathrm{hkl}}=\frac{a_{\mathrm{hkl}}-a_{0}}{a_{0}}=\left(2 S_{1}^{\mathrm{hkl}}+\frac{1}{2} S_{2}^{\mathrm{hkl}} \sin ^{2} \psi\right) \sigma_{\mathrm{biax}}$,

where $S_{1}^{\text {hkl }}$ and $S_{2}^{\text {hkl }}$ are the so-called X-ray elastic constants (XECs) for the $\{\mathrm{hkl}\}$ reflections employed in the diffraction measurements, and $\mathrm{a}_{0}$ is the stress-free lattice parameter. The XECs differ from the mechanical elastic constants, $S_{1}^{\text {mech }}=-v /$ E and $S_{2}^{\text {mech }}=2(1+v) /$ E, usually employed to describe the behavior of isotropic polycrystalline aggregates, where $\mathrm{E}$ is the Young modulus and $v$ is the Poisson ratio. For TiN, due to the relatively small (single-crystal) elastic anisotropy, the difference between XECs and mechanical elastic constants, as derived from various grain-interaction models, is rather small. The XECs were 
Table 2

Results of XRD stress analysis using $\sin ^{2} \psi$ method.

\begin{tabular}{|c|c|c|c|c|c|c|c|}
\hline & \multirow[t]{2}{*}{$\Gamma_{\mathrm{hkl}}$} & \multirow[t]{2}{*}{$S_{1}^{\mathrm{hkl}}\left(\mathrm{TPa}^{-1}\right)$} & \multirow[t]{2}{*}{$\frac{1}{2} S_{2}^{\mathrm{hkl}}\left(\mathrm{TP}^{\mathrm{a}-1}\right)$} & \multicolumn{2}{|l|}{$\sigma_{\text {biax }}(\mathrm{GPa})$} & \multicolumn{2}{|l|}{$\mathrm{a}_{0}(\mathrm{~nm})$} \\
\hline & & & & $\lambda=50 \mathrm{~nm}$ & $\lambda=100 \mathrm{~nm}$ & $\lambda=50 \mathrm{~nm}$ & $\lambda=100 \mathrm{~nm}$ \\
\hline$\{200\}$ & 0 & -0.38 & 2.36 & $-5.4 \pm 0.2$ & $-5.4 \pm 0.2$ & 0.4242 & 0.4244 \\
\hline$\{311\}$ & 0.157 & -0.47 & 2.64 & $-6.3 \pm 0.3$ & $-5.1 \pm 0.4$ & 0.4244 & 0.4241 \\
\hline
\end{tabular}

calculated for the $\{200\}$ and $\{311\}$ reflections from the single-crystal compliance components $\mathrm{s}_{11}=1.98 \mathrm{TPa}^{-1}, \mathrm{~s}_{12}=-0.38 \mathrm{TPa}^{-1}$ and $\mathrm{S}_{44}=5.92 \mathrm{TPa}^{-1}$ taken from [16] and assuming a Reuss model (i.e. equal stress state for all crystallites; see Appendix A of [17] for the detailed expressions). The calculated XECs together with the results of stress analysis are reported in Table 2. One can see that the stress level reaches -6 to $-5 \mathrm{GPa}$ in TiN, independently of the bilayer thickness. The strong ion bombardment involved in the arc deposition process is known to create defects inside TiN crystallites, acting as misfitting particles at the origin of compressive stress [18], a phenomenon often referred as atomic peening. Such stress levels (up to $-7 \mathrm{GPa}$ ) are typically reported in the literature for arc-deposited polycrystalline TiN films [19]. The stress-free lattice parameter of TiN layers is found to be equal to the bulk value $(0.4242 \mathrm{~nm})$, confirming a purely biaxial stress state [18] and the absence of significant impurity concentration in the crystallites.

Cross-section SEM micrographs of the nanostructured coating are presented in Fig. 4a, alternating nanoscale layers can be easily seen in Fig. 4b, dark layers correspond to TiN, and light layers correspond to MoN.

High resolution microscopy (HR-TEM) was used to characterize the structure of the multilayered system with the $\lambda=50 \mathrm{~nm}$ average period.

The TEM dark-field images in Fig. 5 show columnar growth of the multilayer nitride system. It starts from interface between the $\{111\}$ textured steel substrate and the multilayer, or from within the multilayer.

Slightly bent grains extend across nitride layers and interfaces, and are $20-100 \mathrm{~nm}$ large and $100-500 \mathrm{~nm}$ long. A $100 \mathrm{~nm}$ thin interlayer is visible and contains $\mathrm{Ti}, \mathrm{Mo}, \mathrm{C}$ and traces of $\mathrm{N}$ as evidenced by EDS mapping. This interlayer doesn't show any texture, is well crystallized and also contains columnar grains. A structural modulation with a period $\sim 5 \mathrm{~nm}$ can be seen within the interlayer, as shown in the bright-field and Fast-Fourier-Transform (FFT) images in Fig. 6. This type of modulation has been observed in several metallic carbides which contain Ti or Mo and exhibit a superstructure due to the incorporation of impurity atoms in the lattice $[20,21]$.

The first layer grown on top of this interlayer is a $5 \mathrm{~nm}$ thin titanium nitride, then followed by a $20 \mathrm{~nm}$ molybdenum nitride and a $40 \mathrm{~nm}$ titanium nitride again (see Fig. 5). The sequence was then repeated until the multilayer reached a total thickness of about $8 \mu \mathrm{m}$. It has been reported that $(\mathrm{Mo}, \mathrm{Ti}) \mathrm{C}$ compound is fcc with a lattice parameter of a $0.426 \mathrm{~nm}[22]$. The mismatch with TiN being close to zero, which allows for local epitaxy $(111)_{\mathrm{MoTi}} / /(111)_{\mathrm{TiN}}$.

A typical diffraction pattern from the multilayer is shown in Fig. 7a. Here an area encompassing about 10 alternating layers was selected. Spots randomly distributed on circles labeled from 1 to 5 indicate layers with polycrystalline character. All spots in this diffraction pattern could be indexed with reflections belonging to fcc TiN and cubic $\gamma-\mathrm{Mo}_{2} \mathrm{~N}$. Adjacent circle nos. 1 and 2 cross 111 spots and bear witness for local lattice parameter variation of about $2-3 \%$ within the nitride layers, so do circles 4 and 5 which cross 220 spots, while circle 3 goes through 200 spot. In the high-resolution TEM image shown in Fig. 7b, both titanium and molybdenum nitride layers appear well crystallized with thicknesses of $40 \pm 5 \mathrm{~nm}$ and $20 \pm 5 \mathrm{~nm}$, respectively. Partial epitaxy occurs between adjacent $\mathrm{Mo}_{2} \mathrm{~N}$ and TiN layers. Randomly oriented and distributed Moiré patterns extending over few nanometers are frequently observed, especially in molybdenum nitride layers. All layers are only weakly textured (if at all) with $\{100\}$ orientation seen more frequently than $\{111\}$. Titanium nitride layers contain $5-30 \mathrm{~nm}$ size grains and are unambiguously identified as stoichiometric TiN. From most HRTEM images of the molybdenum nitride layers, all of which are fine grained (5-10 nm size), a good match was found with $\gamma-\mathrm{Mo}_{2} \mathrm{~N}$. However, in some cases FFTs reveal interplanar distances corresponding to non-cubic molybdenum nitrides - possibly strongly distorted $\mathrm{Mo}_{2} \mathrm{~N}$ or tetragonal $\mathrm{Mo}_{2} \mathrm{~N}$ - as reported by other authors [23,24]. FFTs acquired at few microns from the substrate in the molybdenum nitride layer, showed some SAED spots (such as one yielding an interplanar distance of $0.185 \mathrm{~nm}$ ) that were consistent with $02-22$ reflection from hexagonal MoN. The main reason for two-phase state appearing was intensive ion bombardment, which led to nanograins grinding and forming of interphase boundaries. Separate $\gamma-\mathrm{Mo}_{2} \mathrm{~N}$ layers with cubic lattice were formed and it caused forming of interphase boundary.

We investigated mechanical characteristics using nanoindentation method and we found, that the highest hardness of $~ 30$ GPa was achieved for $\lambda=50 \mathrm{~nm}$ period multilayered coating. Increasing the period to $100 \mathrm{~nm}$ or decreasing to $25 \mathrm{~nm}$ led to decreasing of the hardness
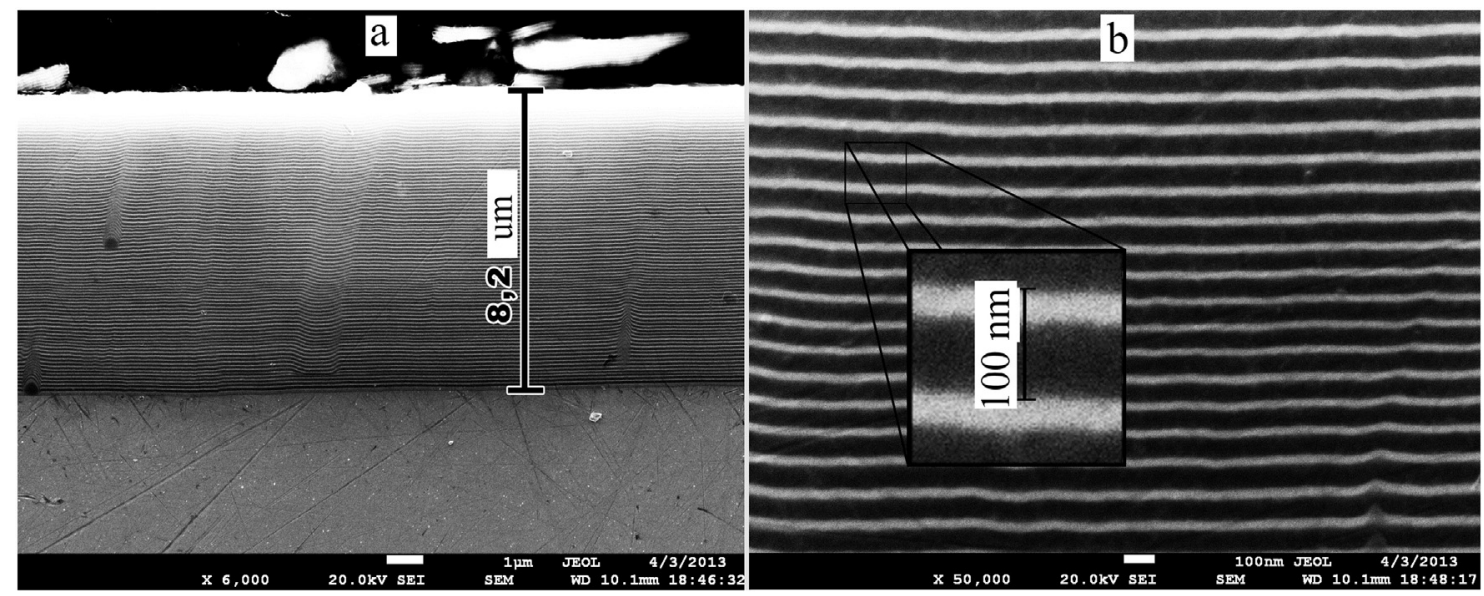

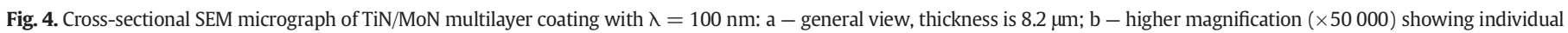
layer thickness. 

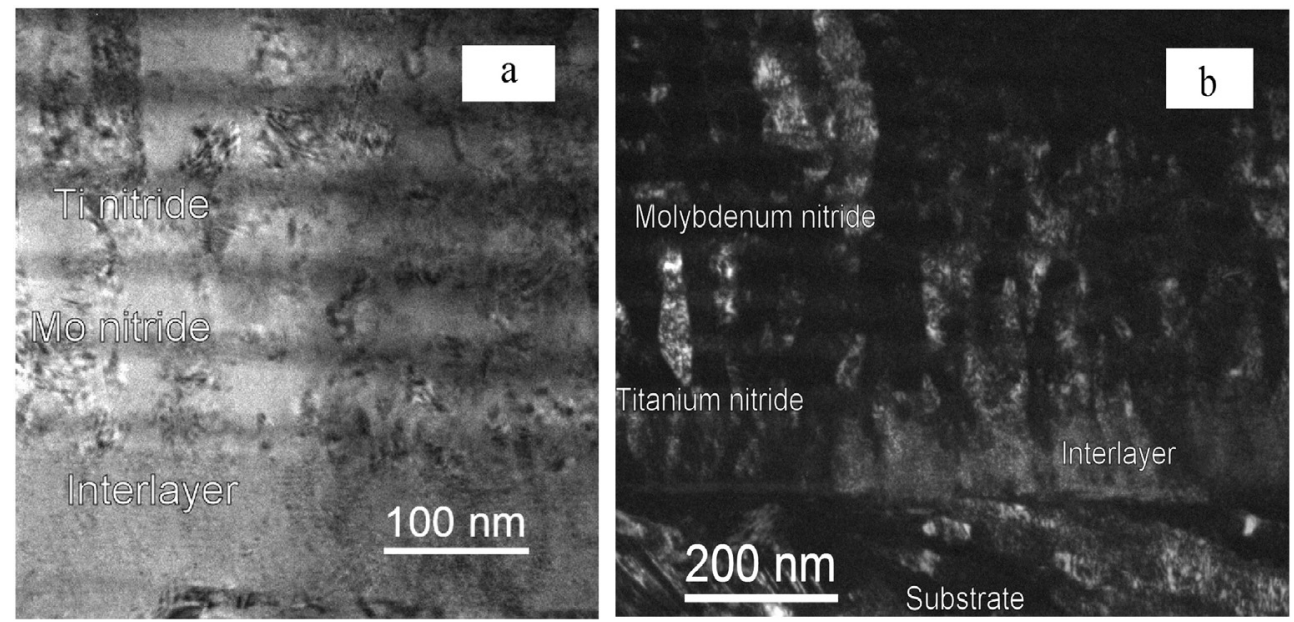

Fig. 5. TEM bright field (a) and dark field (b) images showing the substrate, the interlayer and the TiN and MoN layers.

to the value of $26 \mathrm{GPa}$, which is rather similar to the value of hardness of single-layered TiN coating (about $23 \mathrm{GPa}$ ). Elasticity modulus of the investigated coatings varied from $325 \mathrm{GPa}$ (for $\lambda=25 \mathrm{~nm}$ ) to $420 \mathrm{GPa}$ (for $\lambda=50 \mathrm{~nm}$ ), see Table 3 .

Thus, the obtained multilayered coatings have high hardness, which is more than $25 \%$ higher than the hardness of composing nitrides. Plasticity index is rather high and it allows using such coatings as protective under the influence of different alternating loadings and abrasive wear [25-30]. For multilayered TiN/MoN system we found that the lowest value of $\mathrm{L}_{\mathrm{c} 3}$ critical loading was $42.5 \mathrm{~N}$ (see Table 3 ), and it corresponds to periodical structure with the biggest period of $100 \mathrm{~nm}$. If the period was $50 \mathrm{~nm}$ these critical loading value increased up to $61.0 \mathrm{~N}$, and for the smallest $25 \mathrm{~nm}$ period $\mathrm{L}_{\mathrm{c} 3}$ reached $64.8 \mathrm{~N}$. Thus, using of very thin layers in multilayered system leads to increasing of specific density of interphase boundaries per volume units, in turn, it leads to increasing of critical loading of destruction.

The main experimental results are summarized in Table 3, together with the different methods of the analysis used.

\section{Summary and conclusions}

Thus, we can state, that investigations of the influence of bilayer period on structure-phase state of TiN/MoN coatings showed that the smallest $25 \mathrm{~nm}$ period led to state with phase ratio 90/10 respectively. Increasing the period of TiN/MoN layers up to $50 \mathrm{~nm}$ led to forming of two-phase structure state with an average content of TiN and $\gamma-\mathrm{Mo}_{2} \mathrm{~N}$ cubic phases equal to 60 vol.\% and 40 vol.\%. For samples with more thick TiN and $\mathrm{Mo}_{2} \mathrm{~N}$ layers $(\lambda \approx 100 \mathrm{~nm})$ volume fraction of phases is 70 at.\% for TiN and 30 at.\% for $\mathrm{Mo}_{2} \mathrm{~N}$. Also we can state that the stress level reaches -6 to $-5 \mathrm{GPa}$ in TiN, independently of the bilayer thickness. The strong ion bombardment involved in the arc deposition process is known to create defects inside TiN crystallites, acting as misfitting particles at the origin of compressive stress, a phenomenon often referred as atomic peening. The stress-free lattice parameter of TiN layers is found to be equal to the bulk value $(0.4242 \mathrm{~nm})$, confirming a purely biaxial stress state and the absence of significant impurity concentration in the crystallites.

Randomly oriented and distributed Moiré patterns extending over few nanometers are frequently observed, especially in molybdenum nitride layers. All layers are only weakly textured (if at all) with $\{100\}$ orientation seen more frequently than $\{111\}$. Titanium nitride layers contain 5-30 nm size grains and are unambiguously identified as stoichiometric TiN. From most HRTEM images of the molybdenum nitride layers, all of which are fine grained (5-10 nm size), a good match was found with $\gamma-\mathrm{Mo}_{2} \mathrm{~N}$. The main reason for two-phase state appearing was intensive ion bombardment, which led to nanograins grinding and forming of interphase boundaries. Separate $\gamma-\mathrm{Mo}_{2} \mathrm{~N}$ layers with cubic lattice were formed and it caused forming of interphase boundary.

We found, that the highest hardness of $\sim 30 \mathrm{GPa}$ was achieved for $\lambda=50 \mathrm{~nm}$ period multilayered coating. Increasing of the period to $100 \mathrm{~nm}$ or decreasing it to $25 \mathrm{~nm}$ led to decreasing of the hardness to the value of $26 \mathrm{GPa}$, which is rather similar to the value of hardness of single-layered TiN coating (about $23 \mathrm{GPa}$ ). Elasticity modulus of the investigated coatings varied from $325 \mathrm{GPa}$ (for $\lambda=25 \mathrm{~nm}$ ) to $420 \mathrm{GPa}$ a

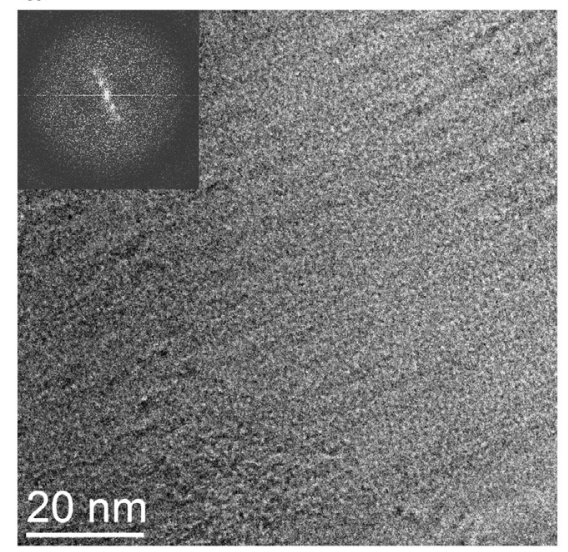

b

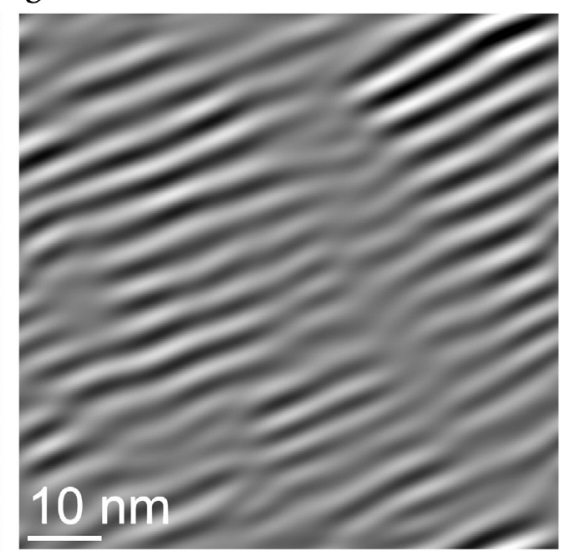

Fig. 6. TEM bright-field (a) and FFT-filtered image (b) of the interlayer grown between the substrate and the multilayer. The FFT is shown in the inset. 
a

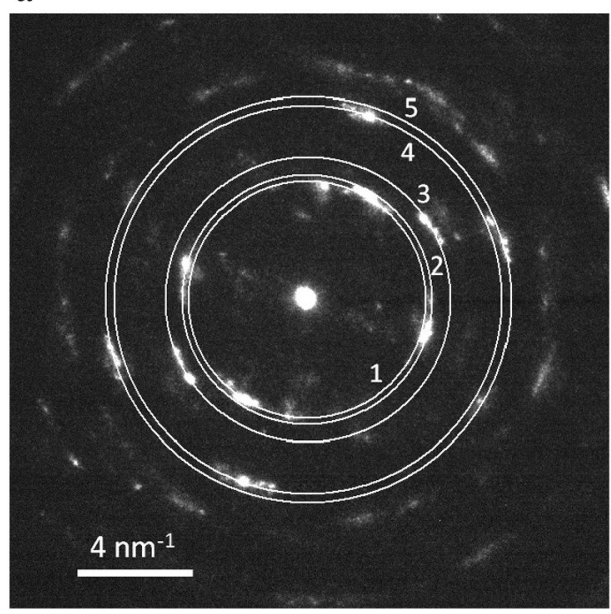

b

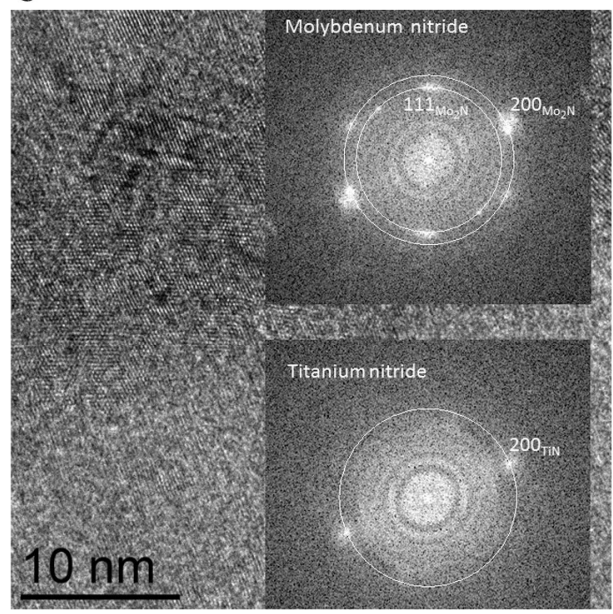

Fig. 7. SAED pattern from the multilayer (a) and FFTs from the HR-TEM images of the titanium and molybdenum nitride layers (b).

Table 3

Summarized results of coating's investigation.

\begin{tabular}{|c|c|c|c|c|c|c|}
\hline \multirow[t]{2}{*}{ Material and period } & \multirow[t]{2}{*}{ Phase ratio $\mathrm{TiN} / \gamma-\mathrm{Mo}_{2} \mathrm{~N}$} & \multicolumn{2}{|l|}{ Concentration, at.\% } & \multirow[t]{2}{*}{ Hardness, GPa } & \multirow[t]{2}{*}{ Elasticity Modulus, GPa } & \multirow[t]{2}{*}{ Critical Load, $\mathrm{L}_{\mathrm{c} 3}$} \\
\hline & & $\mathrm{Ti}$ & Mo & & & \\
\hline $\mathrm{TiN} / \mathrm{MoN}, \lambda=25 \mathrm{~nm}$ & 90/10 (by XRD) & 86.47 (by EDS) & 13.53 & 26 (by CSM) & 325 (by CSM) & 64.8-66.2 (by REVETEST) \\
\hline $\mathrm{TiN} / \mathrm{MoN}, \lambda=50 \mathrm{~nm}$ & 60/40 (by XRD, TEM, HRTEM) & 62.3 (by EDS, RBS, SIMS) & 36.8 & 30 (microhardness test) & 420 (by CSM) & 61.0-63.2 (by REVETEST) \\
\hline $\mathrm{TiN} / \mathrm{MoN}, \lambda=100 \mathrm{~nm}$ & 70/30 (by XRD) & 68.4 (by EDS, RBS) & 31.6 & 27 (by CSM) & 390 (by CSM) & 42.5-45.8 (by REVETEST) \\
\hline
\end{tabular}

(for $\lambda=50 \mathrm{~nm}$ ). For multilayered TiN/MoN system we found, that the lowest value of $\mathrm{L}_{\mathrm{c} 3}$ critical loading was $42.5 \mathrm{~N}$, and it corresponds to periodical structure with the biggest period of $100 \mathrm{~nm}$. If the period was $50 \mathrm{~nm}$ these critical loading value increased up to $61.0 \mathrm{~N}$, and for the smallest $25 \mathrm{~nm}$ period $\mathrm{L}_{\mathrm{c} 3}$ reached $64.8 \mathrm{~N}$. Thus, the use of very thin layers in multilayered system leads to increasing of specific density of interphase boundaries per volume units, in turn, it leads to increasing of critical loading of destruction.

\section{Acknowledgments}

This work was done under the aegis of scientific-technical collaboration program between Sumy State University (Sumy, Ukraine) and University of Poitiers (Institut P', University of Poitiers, Poitiers, France), and Ukrainian complex state budget programs "Creation of basis of superhard nanostructure coatings fabrication with high physical and mechanical properties" (registration number 0112U001382) and "Physical principles of plasma technologies for complex treatment of multicomponent materials and coatings" (registration number 0113U000137c).

The authors are thankful to Prof. Komarov F.F. for his help in providing of RBS analysis, Andreev A.A. for his help in coating fabrication, Prof. Chartier P. for his help in microindentation measurements, and Prof. Konarski P. for his help in SIMS measurements.

\section{References}

[1] Meng Q, Wen M, Liu P, Zhang K, Zheng W. Correlation between interfacial electronic structure and mechanical properties of $\mathrm{ZrN}_{\mathrm{SiN}}$ films. Mater Lett 2013:94:61-4.

[2] Abadias G, Guerin Ph. In situ stress evolution during magnetron sputtering of transition metal nitride thin films. Appl Phys Lett 2008;93(11) [111908-111908-3].

[3] Soderberg H, Oden M, Larsson T, Hultman L, Molina-Aldareguia JM. Epitaxial stabilization of cubic-SiN ${ }_{x}$ in TiN/ SiN $_{x}$ multilayers. Appl Phys Lett 2006;88(19):191902-1-3.

[4] Pogrebnjak AD. Investigation of element profiles, defects, phase composition and physical and mechanical properties of superhard coatings Ti-Hf-Si-N. Mater Sci Appl 2013:4(4a):24-31.

[5] Wen M, Meng Q, Hu C, Au T, Su Y, Yu W, et al. Structure and mechanical properties of $\sigma-\mathrm{NbN} / \mathrm{SiN}_{\mathrm{x}}$ and $\sigma^{\prime}-\mathrm{NbN} / \mathrm{SiN}_{\mathrm{x}}$ nano-multilayer films deposited by reactive magnetron sputtering. Surf Coat Technol 2009;203:1702-8.
[6] Lao J, Shao N, Mei F, Li G, Gu M. Mutual promotion effect of crystal growth in TiN/SiC nanomultilayers. Appl Phys Lett 2005;86:011902-1-3.

[7] Setoyama M, Nakayama A, Tanaka M, Kitagawa N, Nomura T. Formation of cubic AlN in TiN/AlN superlattice. Surf Coat Technol 1996;86-87:225-30.

[8] Gassner G, Mayrhofer PH, Kutschey K, Mitterer C, Kathrei M. Magneli phase formation of PVD Mo-N and W-N coatings. Surf Coat Technol 2006;201:3335-44.

[9] Pogrebnjak AD, Bratushka SN, Boyko VI, Shamanin IV, Tsvintarnaya YuV. A review of mixing process in $\mathrm{Ta} / \mathrm{Fe}$ and $\mathrm{Mo} / \mathrm{Fe}$ systems treated by high current electron beams. NIM B 1998;145(3):373-90.

[10] Nordin M, Larsson M, Hogmark S. Mechanical and tribological properties of multilayered PVD TiN/CrN, TiN/MoN, TiN/NbN and TiN/TaN coatings on cemented carbide. Surf Coat Technol 1998;106:234-41.

[11] Musil J. Hard nanocomposite coatings: thermal stability, oxidation resistance and toughness. Surf Coat Technol 2012;207:50-65.

[12] Martev IN, Dechev DA, Ivanov NP, Uzunov TsD, Kashchieva EP. Nanolaminated TiN/ $\mathrm{Mo}_{2} \mathrm{~N}$ hard multilayer coatings. J Phys Conf Ser 2010;223(1):012-9.

[13] Pogrebnjak AD, Shpak AP, Azarenkov NA, Beresnev VM. Structures and properties of hard and superhard nanocomposite coatings. Phys Usp 2009;52(1):29-54.

[14] Pogrebnjak AD, Sobol OV, Beresnev VM, Turbin PV, Kirik GV, Makhmudov NA, et al. Phase composition, thermal stability, physical and mechanical properties of superhard on base Zr-Ti-Si-N. Nanostructured Materials and Nanotechnology IV: Ceramic Engineering and Science Proceedings, vol. 31, Is. 7. Nanocomposite coatings; 2010. p. 127-38.

[15] Ivasishin OM, Pogrebnjak AD, Bratushka SN. Nanostructured layers and coating formed by ion-plasma fluxes in titanium alloys and steels. Kyiv: Akademperiodyka; 2011285.

[16] Abadias G, Ivashchenko VI, Belliard L, Djemia Ph. Structure, phase stability and elastic properties in the $\mathrm{Ti}_{1}-{ }_{\mathrm{x}} \mathrm{Zr}_{\mathrm{x}} \mathrm{N}$ thin-film system: experimental and computational studies. Acta Mater 2012;60:5601-14.

[17] Welzel U, Ligot J, Lamparter P, Vermeulen AC, Mittemeijer EJ. Stress analysis of polycrystalline thin films and surface regions by X-ray diffraction. J Appl Cryst 2005;38:1-29.

[18] Kamminga J-D, de Keijser ThH, Delhez R, Mittemeijer EJ. On the origin of stress in magnetron sputtered TiN layers. J Appl Phys 2000;88:6332-45.

[19] Bendavid A, Martin PJ, Wang X. Wittling M, Kinder TJ. Deposition and modification of titanium nitride by ion assisted arc deposition. J Vac Sci Technol A 1995;13(3): $1658-64$.

[20] Kazdaev KR, Abylkalykova RB, Kveglis LI. Regularities of formation of the ordered structures in molybdenum at ion implantation. J Sib Fed Univ Eng Technol 2012;5:560-7.

[21] Gusev AI, Rempel AA, Magerl AJ. Disorder and order in strongly nonstoichiometric compounds: transition metal carbides, nitrides and oxides. N.-Y.: Springer; 2001608

[22] Yen HW, Huang CY, Yang JR. Characterization of interphase-precipitated nanometersized in a Ti-Mo-bearing steel. Scr Mater 2009;61:616-9.

[23] Machon D, Daisenberger D, Soignard E, Shen E, Kawashima T, Takayama-Muromachi $\mathrm{E}$, et al. High pressure-high temperature studies and reactivity of $\mathrm{Mo}_{2} \mathrm{~N}$ and $\mathrm{MoN}$. Phys Status Solidi A 2006;203(5):831-6.

[24] Jones A, Hitchman ML, editors. Chemical vapour deposition: precursors, processes, and applications. Cambridge: RSC Publishing; 2009. p. 419. 
[25] Dub SN, Novikov NV. Testing of solids for nanohardness. J Superhard Mater 2004;6: 16-33.

[26] Pogrebnjak AD. Structure and properties of nanostructured (Ti-Hf-Zr-V-Nb)N coatings. J Nanomater 2013 [ID 780125, 12 pages].

[27] Koehler JS. Attempt to design a strong solid. Phys Rev B 1970;2(2):547-51.

[28] Zhang Guojun, Fan Tianxiang, Wang Tao, Chen Hailin. Microstructure, mechanical and tribological behavior of $\mathrm{MoN} / \mathrm{SiN}_{\mathrm{x}}$ multilayer coatings prepared by magnetron sputtering. Appl Surf Sci 2013;274:231-6.
[29] Pogrebnjak AD, Beresnev VM, Bondar OV, Abadias G, Chartier P, Postolnyi BA, et al The effect of nanolayer thickness on the structure and properties of multilayer TiN/MoN coatings. Tech Phys Lett 2014;40(3):215-8.

[30] Musil J, Novak P, Hromadka M, Cerstvy R, Soukup Z, Savkova J. Mechanical and tribological properties of sputtered Mo-O-N coatings. Surf Coat Technol 2013;215:386-92. 